\title{
Vascular Access Steal Syndrome
}

National Cancer Institute

\section{Source}

National Cancer Institute. Vascular Access Steal Syndrome. NCI Thesaurus. Code C115787.

Shunting of blood flow from the arterial to the venous side of a hemodialysis access. 